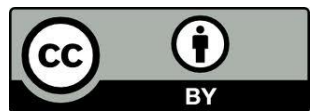

\title{
APRENDIZAGENS COMUNITÁRIAS AFRICANAS DE LONGA DURAÇÃO E EM LARGA ESCALA SEGUNDO A EXPANSÃO BANTA
}

\author{
African Community Learning From Long Term and Large Scale According To Bantu \\ Expansion
}

\author{
Jefferson Olivatto da Silva \\ Doutor em Ciências Sociais - UNESP \\ Universidade Estadual do Centro-Oeste - UNICENTRO \\ e-mail: jeffcassiel@yahoo.com
}

\begin{abstract}
RESUMO: Nesta pesquisa foi utilizada a expansão banta na África subsaariana para investigar os processos de aprendizagem das comunidades bantas, que nesta pesquisa responderá pelos processos de difusão e assimilação de novas aprendizagens sociais. Por uma perspectiva da Antropologia da Educação, baseados em Fredrik Barth sobre fronteiras culturais e identidade étnica foram focalizadas as aprendizagens que compuseram essa difusão linguística durante um longo período histórico e em larga escala entre comunidades identificadas como bantas. As línguas proto-banto começaram a ser difundidas a partir de Camarões, por volta de $4000 \mathrm{AP}$, e modelaram a identidade das comunidades mediante constelações de aprendizagem. Observou-se que as práticas cotidianas, a posição social periférica dos atores e atrizes e interesses comerciais e políticos além de diferentes direcionamentos e momentos dessa difusão linguística perpetuaram práticas culturais similares de longa distância e em larga escala. Com efeito, determinados comportamentos sociais criaram e recriaram sentidos em torno das identidades comunitárias por meio de uma educação escondida: a produção e o uso de cerâmicas, a incorporação de elementos arábico-islâmicos e do sistema numérico suaíli em esquemas simbólicos do interior da África e a mulher como fator agregador de aprendizagens.
\end{abstract}

Palavras chave: Banto, Aprendizagem, África Subsaariana, Mobilidade Social e Antropologia da Educação.

ABSTRACT: It used the linguistic researches about Bantu expansion in Sub-Saharan Africa to inquiry about learning process in Bantu communities. Using Anthropology of Education based on Fredrik Barth's cultural borders and ethnic identity, it aimed on learning milieu related to linguistic diffusion during historical long-term and large-scale among Bantu communities. Proto-Bantu languages started their move in Cameroon aprox. 4000 BP and modeled communities' identity maintenance by learning constellations. Everyday practices, actors' and actress' in peripheral positions, commercial and politic benefits, and different directions and moments could sustain cultural similarities from long-distance and large-scale. As a result, certain social behaviors created and recreated meanings bound to communities' identity by a hidden education: the making and use of pottery, Arab and Islāmic elements and Kiswahili counting system into African hinterland symbolic schemes, and woman-factor of learnings.

Keywords: Bantu, Learning, Sub-Saharan Africa, Social Mobility, Anthropology of Education.. 
A partilha de longa duração e em larga escala

A aprendizagem de práticas sociais distintas pode se constituir como um artefato de prestígio e da demanda por resposta diante de necessidades coletivas. Conforme o dinamismo do imaginário coletivo, essas novas disposições se tornam assimiladas e reconhecidas se conseguirem criar sentidos ou se se vincularem aos que já operam nas constelações de aprendizagens.

A difusão de novas aprendizagens por meio da expansão banta e incorporações e sobreposições de posteriores sobre as bantas caracterizam dois movimentos: inicialmente interno a partir do Sudão (movimento pré-proto-banto) e externo pelas costas índicas e atlânticas. Os indicativos desses dois movimentos impulsionaram alterações culturais ocorridas por diferentes sentidos migratórios e em momentos alternados e simultâneos, qual seja, sem corresponder à continuidade unilateral. A expansão banta precisa ser relembrada como uma atribuição e um recorte realizado por interesses etnocêntricos externos à África. Por isso, vale frisar que os estudos sobre os processos migratórios e o acompanhamento das aprendizagens africanas que serão tratados definem esses grupos sobre a perspectiva da classificação linguística dos falantes bantos, como tem sido realizado por Malcolm Guthrie (1967-1971), Jan Vansina (1999) e De Filippo et al. (2012). Usaremos a noção de longa duração e em larga escala para explicar as aprendizagens que acompanharam e foram incorporadas pelos falantes bantos. ${ }^{1}$

Com efeito o processo de aprendizagem ao qual recorremos inspira-se em Fredrik Barth (2000) a respeito de sua concepção de interações étnicas e fronteiras culturais. Para explicar esse processo, Barth (2000) concebe que grupos com traços culturais similares escolhem por interesses específicos sinais diacríticos que os diferenciam de outros grupos em contato. Por essa confrontação os grupos reafirmam os traços que constituem sua identidade per se operando no interior de constelações de categorizações.

Já que essas constelações representam processos cognitivos que coordenam pensamentos e atitudes, levantamos como tese que poderiam ser interpretadas enquanto constelações de aprendizagens a partir de uma visão da Antropologia da Educação.

\footnotetext{
${ }^{1}$ Realizamos uma pesquisa anterior em que demonstramos como essas partilhas foram úteis às comunidades diante das políticas coloniais de saúde, que lhe impuseram tratamentos dolorosos e muitas vezes inócuos (DA SILVA, 2015).
} 
Esses grupos configuraram dinâmicas identitárias modelando-os em comunidades, cuja justificativa para manusearem saberes aconteceria pela reprodução de processos culturais. Portanto, os rituais e as práticas cotidianos operariam por aprendizagens reconhecíveis na comunidade como legítimas por seu poder de prestígio e de status. Ademais novos elementos seriam atraídos para orbitar no interior dessas constelações por conta de interesses oriundos do contato com novos grupos ou indivíduos.

As constelações de aprendizagens que apresentaremos acompanham as migrações no interior da África orbitando em torno da língua banta. Esses grupos difundiram a produção de cerâmicas na África subsaariana, agregaram a seu cotidiano o sistema numérico dos comerciantes árabes e suaíli e promoveram a reprodução da iniciação feminina na África meridional. Em termos lato usamos o sentido de correntes de tradições culturais de Barth (2000). Para o autor tais correntes podem assim ser apreendida: "cada uma delas exibindo uma agregação empírica de certos elementos e formando conjuntos de características coexistentes que tendem a persistir ao longo do tempo, ainda que na vida das populações locais e regionais várias dessas correntes possam misturar-se.” (BARTH, 2000, p. 123). Dessa forma, poderemos contribuir com o desenvolvimento de pesquisas em torno de questões socioeducacionais perpassantes a um longo período histórico e em larga escala geográfica antes da exploração colonial iniciada no final do século XIX.

Aprendizagens bantas

Os processos migratórios bantos puderam gerar alguns contrassensos sobre sua gênese a ponto de ser referenciado ora como expansão banta ora problema banto (BOSTOEN, 2004a; 2007). Antes de mais nada, vale dizer que o termo banto fora cunhado pelo missionário alemão Wilhelm Bleek, em 1851, momento em que submeteu sua tese de estudo comparativo entre as línguas da África do Sul (BOESTEN, 2007).

O problema banto se evidencia quando também são inseridas outras ciências no debate das possíveis direções da mobilidade social na África subsaariana, como é o caso de estudos genéticos das populações (DE FILIPPO et al., 2012), agricultura (RUSSELL; SILVA; STEELE, 2014), pecuária e crises do biossistema (MCKEY; LÉZINE, 2013), corroborando o argumento de aprendizagens comunitárias de longa duração na África subsaariana: Vansina (1985), Holden e Gray (2006) e Bostoen 
(2007). Todavia a expansão banta precisa ser considerada por avanços e regressos de mobilidades sociais em diferentes períodos e direções, descaracterizando o que seria um movimento contínuo e único de aprendizagens (cf. M’Bokolo, 2009). Por isso, prováveis hipóteses se sobrepõe pela atualização geográfica e genética dos dados que sustentam, ainda, uma provável cronologia dos avanços migratórios.

Um dos motivos que produziria a primeira mobilidade de grupos pré-portobanto, conforme os argumentos de Vansina (1999) e Grollemund et al. (2015), consideram que devido a desertificação do Saara vários grupos se direcionaram para as regiões mais férteis ao sul. No caso dos grupos pré-proto-banto, eles teriam partido do Sudão para Camarões. Provavelmente circundando ao norte a região da floresta equatorial. Com efeito há dois pontos sobre a indicativa do contato com esses grupos: a) classificação geográfica das línguas bantas (GROLLEMUND et al., 2015; HOLDEN; GRAY, 2006) pelos estudos em léxico-estatística denominando de banto do oeste, central, do leste e do sudoeste; b) e, o ponto de partida do proto-banto em Camarões, onde são encontrados grupos bantos Nok, Kano, Gao e Kumbi Saleh (HOLDEN; GRAY, 2006).

Como havia apontado De Filippo et al. (2012), houve duas divisões da expansão banta. O início do processo de divisão da língua banta, juntamente com a mobilidade social, dataria de 4000 anos atrás, denominado de divisão inicial e a 2000 anos atrás teria ocorrido a divisão tardia. Após a desertificação do Saara entre 7000 a 6000 anos atrás, os grupos proto-bantos haviam se fixado em Camarões e entrado em aprendido técnicas de produção de cerâmicas, que, segundo escavações de Shum Laka foram encontrados fragmentos de vasilhas anteriores a 4000 AP (AP: antes do presente, isto é, 1950 é o marco presente quando surge a datação por carbono $14-\mathrm{C}^{14}$ ). Após um longo período de contato com essas técnicas teria acontecido dois direcionamentos, denominados de divisão inicial e tardia. A primeira foi em direção ao leste e sua ramificação para o sul e outro ao sul da floresta equatorial, próximo à savana e de lá subdividindo-se para a região austral e sudeste. A divisão inicial aparenta ainda ser frágil, tendo em vista a hipótese de Vansina (1985) que nesse momento as populações bantas precisariam se adaptar à floresta equatorial por conta de predadores, às novas 
doenças e às populações não-bantas ou autóctones ${ }^{2}$ que ali se encontravam. Os dois primeiros fatores de adaptação ecológica responderiam pela diminuição do uso de técnicas de agricultura, fazendo os bantos assimilarem técnicas equatoriais de coleta, pesca e cuidados de saúde.

Cada equilíbrio demográfico envolvido é bastante complexo: a adaptação de um determinado grupo a um nicho natural é afetada por seu tamanho absoluto, mas a adaptação de um grupo étnico ao nicho constituído por um outro é afetada por seu tamanho relativo. (BARTH, 2000, p. 42). [grifo do autor].

A divisão tardia foi intensificada por volta de 3000 a 2500 AP pela formação do corredor de savana devido ao recuou da floresta equatorial, à noroeste e à sudeste. Nesse período os grupos bantos puderam propagar significativamente a língua aliada à fabricação e uso de cerâmicas e da agricultura para a costa leste e ao longo e ao sul do Lago Tanganica, acompanhando o Vale do Rift (BOSTOEN, 2004b; 2007; GROLLEMUND et al. 2015). Interessante observar, segundo Grollemund et al. (2015, p. 2), que as línguas do leste classificados pela letra " $D$ " correspondem à divisão tardia $2.500 \mathrm{AP}$, que se originaram após a difusão ter chegada a sul do Lago Tanganica (figura 1-b), reelaborando esquemas de aprendizagens bantas que ali teriam se instalado com as comunidades autóctones desde o período da divisão inicial (figura 1-a).

Figura 1 - Os dois principais modelos de expansão das línguas bantas

(a)

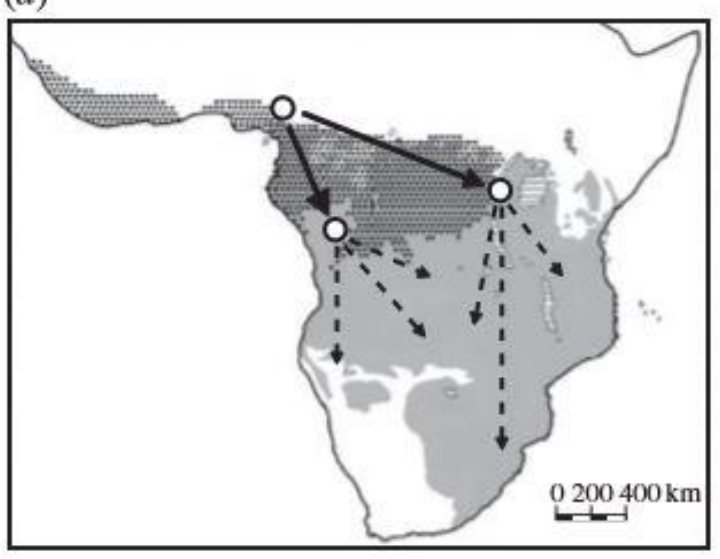

(b)

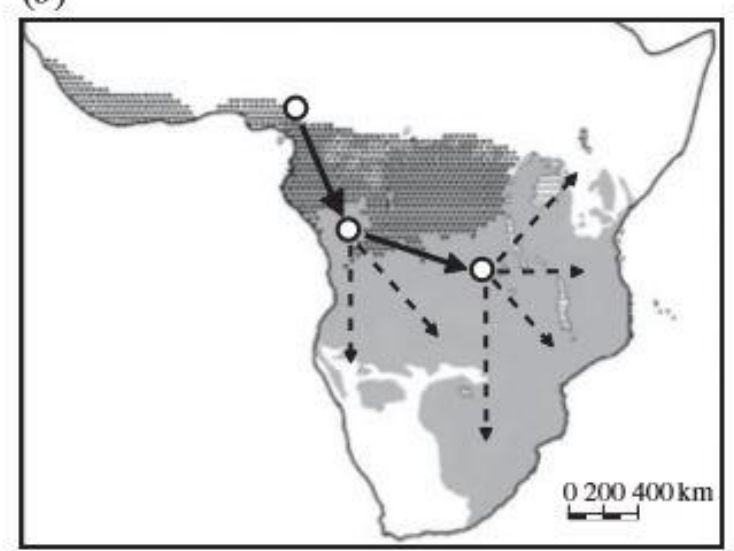

\footnotetext{
${ }^{2}$ Um cuidado que precisa ser tomado pelo uso de autóctone, já que se não se especificar se o grupo é falante banto ou não, dependendo do momento histórico das migrações, o termo é atribuído para populações que fizeram parte da migração banta em estágios anteriores ou que pertenciam a outros grupos Niger-Congo, Khoisano, Nilo-Saariano ou Afro-Asiático.
} 
Fonte: DE FILIPPO et al., 2012, p. 3257.

A parte em cinza corresponde à área de pelas línguas bantas e a parte mais escura a extensão da floresta equatorial. a) divisão inicial e b) divisão tardia.

Esse período pode proporcionar a difusão de novos sistemas linguísticos por situações de prestígio dos vilarejos bantos serem mais numerosos e de organização diferenciada em comparação às comunidades autóctones, corroborando a legitimidade das comunidades bantas para a organização comercial e política. Como afirma Barth (2003), a identidade étnica de um grupo deve ser analisada tendo em conta as experiências, as ações, através das quais ela é formada, o que segundo nossa hipótese corrobora a noção de aprendizagem em termos cotidianos.

Enquanto indício material podemos acompanhar Olivier Gosselain (1999) em sua expansão interpretativa do uso da cerâmica na África. De acordo com Gosselain (1999), a produção de cerâmicas demarcaria proscrições sociais, status e casamento. Haveria a expansão de aprendizagens sociais em torno de sua produção e de uso operacionalizando traços coletivos e compartilhados. Como a Figura 2 demonstra essa pesquisa cobriu uma vasta região desde o extremo oeste do Sahel entre os Serer até a África do Sul entre os Zulu.

Pela difusão do uso da cerâmica e a importância de sentidos sociais atribuídas a ela, constata-se a necessidade de que tenha ocorrido por um longo período, anterior à divisão inicial dos proto-bantos. Essa produção, nas palavras de Gosselain (1999), envolveu a cadeia operatória (chaîne operatoire) delimitando a produção. Assim há prescrições e proscrições comunitárias sobre as quais a técnica precisa acontecer: a escolha do material, o momento propício e o local da colheita de argila, a posição social do(a) ceramista, o significado holístico do fazer, os cuidados com a temperatura, elementos que temperam a cerâmica após retirá-la do forno e seu fim último. Mesmo com variações como local onde retirar a argila e o gênero do(a) ceramista, Gosselain (1999) considera ser a transformação o denominador comum intrínseco a cadeia operatória: transformação fisiológica (nascimento a falecimento), cultural (iniciação e casamento) e mítica (criação da humanidade). Como afirma o autor, as cerâmicas ocupam essa posição metafórica entre as 102 comunidades pesquisadas organizando situações comunitárias rotineiras (relação sexual entre casais) e eventos de magnitude coletiva (morte e sucessão de chefes).

Ademais a dinâmica social orbitaria por lógicas similares denominadas de 
filosofia termodinâmica por De Heusch (1972). Objetivos, gêneros, animais, doenças e eventos sociais estariam classificados por quentes e frios. Assim muito provavelmente a doença tenha sido interpretada como quente pela compreensão holística de situações febris gerada por diversas formas de infecções (alimentares, perfurações corporais e doenças). A aprendizagem dessa cadeia operatória proporciona interrelacionar objetos e sentidos coletivos da produção humana no seu entorno. Entre os Thonga, Pedi e Zulu os recém-nascidos são tratados em termos similares à pós-produção de cerâmicas postos sobre o fogo como defumados, ou aspergidos com água, ou lavados com água misturada com cinzas (DE HEUSCH, 1982). Entre os ceramistas Yoruba da Nigéria o poço de argila é comparado ao ventre ou a vagina de Iya Mapo, a entidade profissional (BEIER, 1980). Também uma mulher Ndebele da África do Sul afirma que o processo inicial de molhar a argila seca é a união entre os elementos feminino (argila) e o masculino (água), devendo dormirem uma noite juntos antes que o trabalho seja iniciado (KRAUSE, 1985). Entre os Bemba da Zâmbia, as cerâmicas preparadas para a iniciação feminina são conhecidas por mbusa, tendo o sentido de emblemas sagrados, que transformam a menina em mulher (RASING, 1994). Esses relatos evidenciam uma compreensão holística entre o fazer (aprender a se tornar) humano e o fazer vasilhas de cerâmica.

Tais processos que foram assimilados em práticas cotidianas e ocupando uma posição de destaque significou uma mudança de percepção sobre o objeto e as relações simbólicas que poderiam estabelecer (BARTH, 2000). Outros fazeres cotidianos deixarem de orbitar nas categorizações primordiais da identidade coletiva ou se tornaram periféricos. Por meio dessa dinâmica seletiva de aprendizagens e significados, algumas aprendizagens deixaram de proporcionar recompensas sociais comparadas aos usos das cerâmicas. 
Figura 2 - Produção de cerâmicas como ordenação social

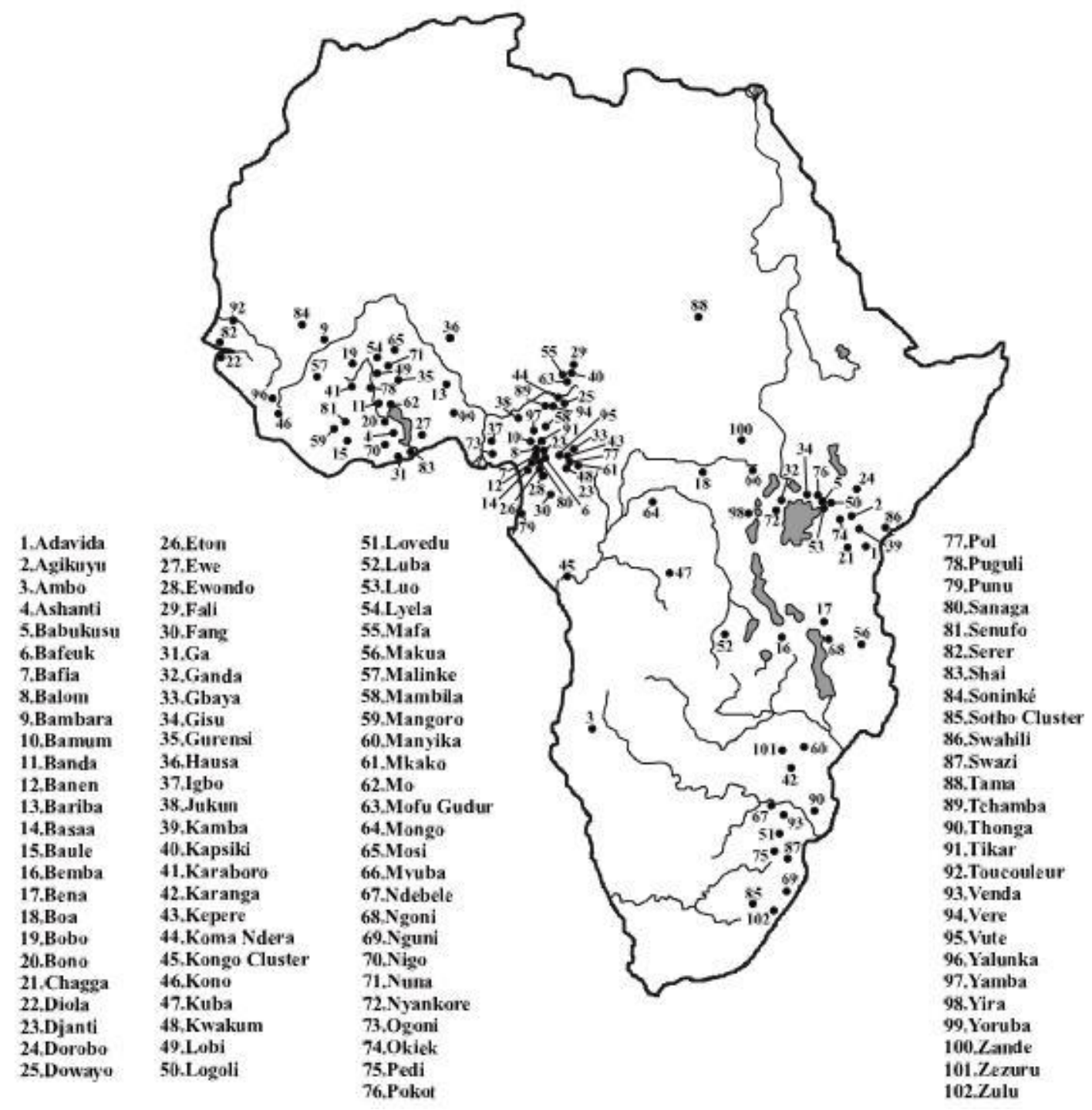

Fonte: GOSSELAIN, 1999, p. 207.

Propagação e interações simbólicas árabes

Entendendo que vários grupos migrantes colaboraram no desenvolvimento das populações africanas e a diversificação de seus sistemas simbólicos, como costumes e línguas, passaremos a ilustrar as prováveis interações simbólicas a partir da Península Árabe pelas moções.

Efeitos da mobilidade social que partiram da Península Árabe, para Martin (2008), podem ser rastreados desde 2.000 a.C., espalhados por todo esse Oceano Índico. 
Viajantes árabes acompanharam as monções de inverno para costa africana e as de verão para as asiáticas. Acompanhando esses interesses comerciais, é possível rastrear que os árabes teriam atravessado o Mar Vermelho para instituir postos mercantis na Etiópia, desde 1000 a.C., ou até antes, originários de Saba, ou Iêmen (MOKHTAR, 1990; PAGE, 2005a; DAVIS, 2005). Estabelecendo alianças por casamentos com os Kushitas (ou cushitas), os sabaenos reorganizaram crenças e valores, Falasha, naquilo que seria conhecido como fé judaica. Posteriormente, por volta de 500 a.C., esses fazendeiros se uniram e formaram uma poderosa cidade-estado do Chifre da África, Axum. Esse reino expandiu suas áreas de contanto por meio da exportação de marfim, elefantes para fins militares, mirra, chifres de rinocerontes, pó de ouro entre outros produtos. Esse reino no Chifre da África demarcou fronteiras do extremo leste do mediterrâneo, pela Arábia e Índia até o atual Sri Lanka (MOKHTAR, 1990; PAGE, 2005a). ${ }^{3}$

Entre os séculos VII até o XI, o islamismo foi difundido pelos árabes na África subsaariana por três eventos expansionistas: conquistas militares árabes, instituição de postos comerciais árabes e o trabalho missionário Sufi. Devido à posição geográfica e às conquistas políticas, os mercadores árabes dominaram o comércio de especiarias no Oceano Índico. A aliança por casamentos com a população local facilitou aos árabes assumirem rotas para o interior. Dessa forma, os árabes islamizados propagaram o culto ao Corão nas regiões portuárias da África do leste e nos postos do interior entre as comunidades bantas e não bantas (PAGE, 2005b; DAVIS, 2005).

Para Françoise Le Guennec-Coppens $(1980 ; 2002)$ teriam ocorrido duas ondas migratórias em Hadharmaut, a primeira entre o século VIII e XII e a segunda XVIII e XX. O primeiro período de imigração foi realizado por ações temporárias com interesse comercial e militar representando altos custos aos Sultanatos e com pouca integração com as sociedades locais. Já o segundo momento teria respondido por uma interação intensa. Esses árabes seriam originários de Hadhramaut e Yaman, - ambas as regiões do atual Iêmen - e movidos pela falta de oferta de terras pela densidade demográfica, longos períodos de secas seguidos de enchentes, fome, epidemias, guerras, conflitos armados e invasões de domínios vizinhos. Esse período da diáspora Hadharmi, que contava em sua maioria imigrantes camponeses, artesãos e mercadores, pôde ser

\footnotetext{
${ }^{3}$ Vale lembrar que o rei Ezana de Axum fora convertido ao catolicismo na primeira metade do século IV, tornando as relações diplomáticas e mercantis de seu reino estratégico para a missionação cristã.
} 
identificado por dois conjuntos de práticas sociais: a inserção da língua árabe Hadharmi encontrada no leste africano (Somália, Quênia e Tanzânia) e a expansão do islamismo.

Pelo convívio gradativo com o islamismo, a partir do século XII, o movimento Sufi, místicos ou monges islâmicos, conquistou vários adeptos na África. Apresentandose por uma prática de tolerância às crenças e costumes locais, esse movimento foi assimilado pelas comunidades subsaarianas, mas, em contrapartida, tornaram-se alvo de perseguições pelo movimento Wahhabi intolerantes à essa interação (GRAY; BIRMINGHAN, 1970). Evidencia-se que os movimentos exotéricos Sufistas estavam presentes na segunda onda migratória árabe, principalmente, e não só dentre os grupos persas e turcos (EL-ROUAYHEB, 2010).

Por isso esse segundo momento predominou o interesse desses árabes em criar vínculos com as comunidades locais, negociando valores e crenças. Com efeito, os laços familiares não seguiam os costumes árabes: os casamentos deixavam de ser endógamos e as esposas tinham diferentes ascendências sociais ou até desconhecidas. A aceitação desses novos membros corroborou algum tipo de vantagens para as comunidades locais, tendo em vista a perspectiva de que essa união poderia ou não ser legitimada para a incorporação de atores estrangeiros:
As condições para essa forma de assimilação claramente envolvem um duplo aspecto: em primeiro lugar, a presença de mecanismos culturais que permitem implementar a incorporação, incluindo-se aí a idéia de obrigações para com os ancestrais, compreensão por pagamento etc.; em segundo lugar, o incentivo representado pelas vantagens evidentes para o grupo doméstico ao qual se dá a incorporação, bem como para seu líder...” (BARTH, 2000, p. 44).

Não obstante, para compreender os efeitos cotidianos da presença desses árabes islamizados, é importante considerar atores e processos periféricos à propagação da interação simbólica - não tão somente clérigos e santos que se instalavam próximos às rotas comerciais.

Nesses termos, McDougall (2013) revela a importância da qual mulheres, porteiros e escravos tiveram na assimilação e propagação de práticas culturais locais ou estrangeiras. No caso da presença do islamismo nas comunidades do interior da costa leste africana, os marcos espaciais como mesquitas, templos e santuários não se constituem como um bom veículo de perscrutar essa história, haja vista sua ausência e a falta de pesquisas arqueológicas nesse sentido. No entanto, Sperling (2000) menciona 
uma outra estratégia presente no cotidiano. As mulheres e os escravos, inclusive as crianças, aprendiam pelo convívio familiar e com outros membros próximos práticas como escrita, leitura, rezas e costumes, inclusive, de pequenos cuidados com a saúde (little medicine) vinculados a um islamismo heterodoxo, ou seja, sem legitimidade e reconhecimento social pelos clérigos ou doutos.

Sperling e Alpers (2000) consideraram a coexistência entre as crenças tradicionais e islâmicas por meio da mediação e negociação que acontecia em lares, varandas e em outros espaços comuns dos vilarejos. O casamento se tornou o principal processo dessa conversão pela delimitação e difusão espacial de aprendizagens islâmicas que adentram regiões distantes da região leste da África Central. Patricia Romero (1988) anteriormente já havia apontado essa tese no que denominou de educação escondida (hidden education), exemplificando com Mama Khadija sendo uma criança liberta havia aprendido o Corão pelas conversas de visitas em sua casa e com sua irmã.

Por isso precisamos constatar que o processo de mediação e negociação entre saberes estruturava-se na criação e recriação de sentidos e categorias de disposições sociais a partir de vínculos afetivos e de dependência. Não obstante, os administradores portugueses em Moçambique atestaram o reconhecimento da estrutura social dessas negociações simbólicas, a ponto de restringirem que os muçulmanos adquirissem escravos para evitar que estes fossem doutrinados por seus senhores (ALPERS, 2000; SPERLING, 2000). Se de um lado a falta de constatações arqueológicas da presença islâmica nas regiões próximas às rotas comerciais do interior, de outro o islamismo foi difundido no cotidiano africano usando a mediação afetiva das tendas e das varandas por atores silenciados pelos registros históricos.

A abrangência da relação entre rotas comerciais do interior até os portos de exportação costeiros pode ser acompanhada no segundo período de expansão árabe, por meio da confecção de mapas e rotas marítimas. Viajantes árabes como Ibn Battuta e Sharif al-Idrisi, no século XII retrataram a costa africana.

A intensidade do processo de negociação simbólica entre costa e interior também é constatada pela expansão do monoteísmo e a formação da língua suaíli (ou Kisuaíli) (MALKKI, 1992). Há indícios de incorporações de esquemas simbólicos monoteístas pelas populações bantas politeístas, majoritariamente. Os Makua que estão 
próximos ao Cabo Delgado, na região norte de Moçambique, pelo fato de apresentarem um sistema religioso monoteísta diferem do panteão das populações vizinhas, provavelmente influenciados pelos muçulmanos desde o século IX ou portugueses cristãos a partir do XVI. Todavia a proximidade dos Makua com os muçulmanos foi muito mais intensa em 1867 devido aos interesses de ambos para expulsar os lusos da ilha de Angoche, Moçambique (NEWITT, 1972).

As comunidades Suaíli (swahili - povos costeiros) se desenvolveram de grupos bantos do norte costeiro da África do leste entre dois universos, a África e o Oceano Índico. Esses grupos bantos chamados de proto-sabaki, no século VI, provavelmente, teriam assumido posições de destaque e propagado em larga escala sua língua sobre as populações autóctones por movimentos migratórios bantos da divisão tardia (cf. DE FILIPPO et al., 2012; ver FIGURA 1b). Nurse e Spear (1985) afirmam que desde o século IX a língua suaíli já era usada amplamente na região norte e por migrações estaria se espalhando para o sul da costa. Esse argumento corrobora a ideia de expansão árabe na costa. E como já apontamos acima sobre a expansão das fronteiras árabes, os Suaíli acompanharam o comércio para o interior e para as regiões costeiras do Índico.

Outro indício material de intenso contato entre as populações pode ser observado como resultado do comércio de sal, óleo de palmeira e ráfia, criando elos entre as populações circundadas pelos lagos Tanganica, Malaui, Muero e as populações da Depressão Upemba - cuja moeda corrente fora as cruzes (ou lingotes) de cobre, desde o século XIII - mas, segundo M'Bokolo (2009), as cruzes mais antigas são datadas do séc. VII, cobrindo um comércio de longa distância, do sudoeste da RDC, Zâmbia e Zimbabue. 
Figura 1 - Cruzes de cobre entre o século XIII e XV

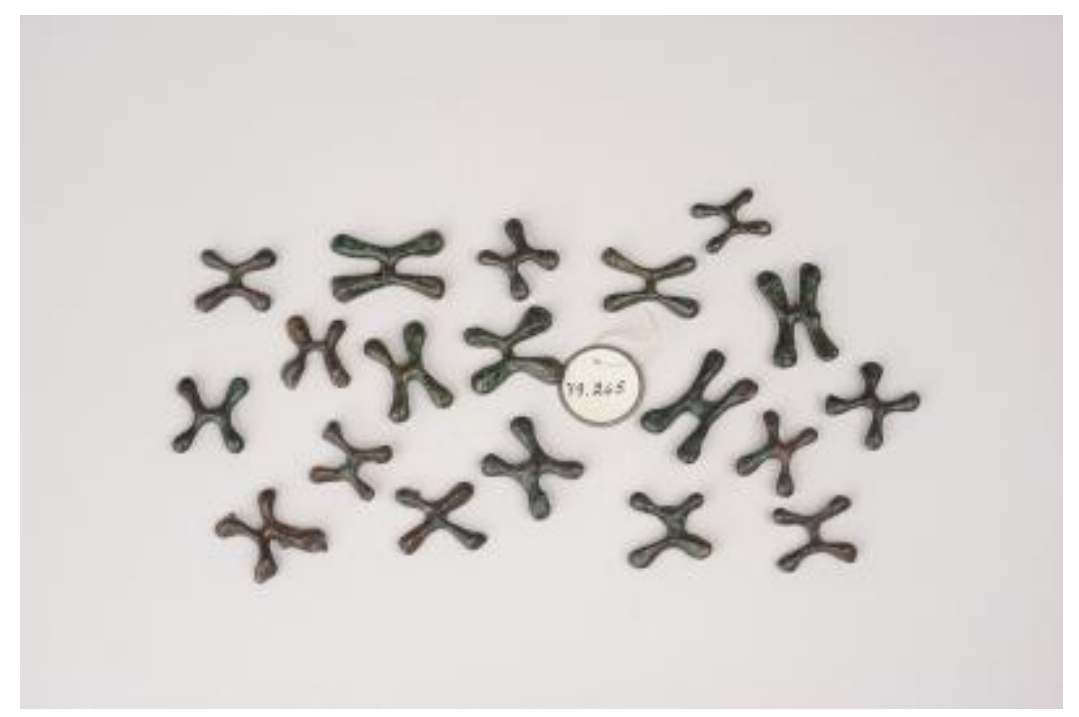

Fonte: RMCA, 2015.

Porém após a estabilização do uso das cruzes no século XVII e sua desvalorização posterior - pelo seu intenso uso diminuindo seu tamanho -, houve a substituição comercial por pérolas no século XIX, que, desde o século XVI eram apreciadas (principalmente, vermelhas e negras ou de Cambay) nas transações comerciais zambezianas. É possível considerar que a valorização dessas contas fosse efeito da influência das caravanas vindas da costa leste, podendo ser observado pelo empréstimo do sistema numérico dos Suaíli no interior dos sistemas numéricos bantos das populações de Uganda até as da África do Sul (NZIEM, 2010, p. 699; DA SILVA, 2012).

A relação comercial e política entre suaíli e árabes e comunidades do interior da África Central foi possível pelos postos comerciais controlados pelo reinado árabe Yeke ou Garanganze de Msiri, localizado na região centro-norte da Zâmbia, norte do rio Luapula, e sul da RDC. Devido ao controle das rotas do interior, cruzando de leste (Índico) a oeste (Atlântico), o rei Msiri contava como aliados os Ovimbundu de Angola, Tippo Tip a oeste do lago Tanganica, Mirambo a leste do Tanganica e os Suaíli na costa índica.

Portanto a mediação das fronteiras culturais fez uso da língua. Se de um lado as línguas bantas se desenvolveram por razões endógenas e exógenas como igualmente foi para a formação da língua suaíli, a negociação do uso desta sobre as outras apontam as transações político-comerciais essa incorporação simbólica intensificou-se. 
Como ilustração, apresentamos o efeito do processo de mediação simbólica ocorrida entre línguas bantas da África Central e o suaíli. Para tanto usaremos o sistema número de um a dez: Suaíli (G41-43), Nyanja (N31), Kikuyu (E51), IshiNdebele (S44) e Chibemba (M42). Somente a última pertence ao grupo linguístico banto central e as outras a do banto do leste. No Quadro 1, os numerais arábicos foram dispostos na primeira coluna e em linhas sua correspondência com outras línguas de contato descritas em colunas. Na última linha apresentamos os países onde atualmente a presença de falantes dessas línguas é significativa e diferenciando-as pelo uso de itálico os países onde são oficiais.

Quadro 1 - Comparativo de similaridade numérica a partir do suá́li

\begin{tabular}{|c|c|c|c|c|c|}
\hline $\begin{array}{l}\text { Numerais/ } \\
\text { Línguas }\end{array}$ & Suaíli & Chibemba & Nyanja & Kikuyu & IshiNdebele \\
\hline 1 & Moja & Cimo & Modzi & Î́mwe & Kunye \\
\hline 2 & Mbili & Fibili & Wiri & Igĩrĩ & Kubili \\
\hline 3 & Tatu & Fitatu & Tatu & Ithatũ & Kuthathu \\
\hline 4 & Nne & Fine & Nayi & Inya & Kune \\
\hline 5 & Tano & Fisano & Sanu & Ithano & Kuyisihlanu \\
\hline 6 & Sita & Mutanda & Sanu n'chimodzi & Ithathatũ & Kuyisithupha \\
\hline 7 & Saba & Cine lubali & Sanu n'ziwiri & Mũgwanja & Kuyisikhombisa \\
\hline 8 & Nane & $\begin{array}{l}\text { Cine konse- } \\
\text { konse }\end{array}$ & Sanu n'zitatu & Inyanya & $\begin{array}{l}\text { Kuyisitshiyanga } \\
\text { lombili }\end{array}$ \\
\hline 9 & Tisa & Pabula & Sanu n'zinayi & Kenda & $\begin{array}{l}\text { Kuyisitshiyanga } \\
\text { lolunye }\end{array}$ \\
\hline 10 & Kumi & Ikumi & Khumi & Ikũmi & Tshumi \\
\hline Países & $\begin{array}{l}\text { Tanzânia, } \\
\text { Quênia, } \\
\text { Uganda, } \\
\text { Burundi, } \\
\text { Ruanda, } \\
\text { Moçambique e } \\
\text { Congo. }\end{array}$ & $\begin{array}{l}\text { Zâmbia, Congo, } \\
\text { Malaui, } \\
\text { Botswana, } \\
\text { Zimbábue } \\
\text { Moçambique. }\end{array}$ & $\begin{array}{l}\text { Malaui, Zâmbia, } \\
\text { Moçambique, } \\
\text { Zimbábue e } \\
\text { África do Sul. }\end{array}$ & Quênia e Tanzânia & $\begin{array}{l}\text { Zimbábue, } \\
\text { Zâmbia, } \\
\text { Botswana, } \\
\text { Lesotho, } \\
\text { Suazilândia, } \\
\text { Namíbia, } \\
\text { Moçambique } \\
\text { África do Sul }\end{array}$ \\
\hline
\end{tabular}

Fonte: Elaborado pelo autor.

Pelo quadro podemos observar: o efeito da negociação das comunidades do interior com o comércio costeiro pelos sultanatos árabes; a incorporação da língua suaíli como parâmetro comercial, atestado pelos numerais de 2 a 5 e 10; a expansão 
geográfica das línguas bantas devido a radiação linguística e mobilidades sociais por razões diversas - pré-coloniais como casamentos e relações político-comerciais; coloniais como zonas de influência para a exploração comercial do interior, guerras e políticas de controle social (VANSINA, 2006; RENAULT, 1992; COSTA E SILVA, 2002).

Aprendizagens escondidas ou silenciosas

As trocas simbólicas entre as populações da África Central instituíram na manutenção social a iniciação de jovens, meninos e meninas. Tanto que Richards (1956) apontou cobrir desde a costa Índica ao Atlântico, ao norte do Congo até a Tanzânia e ao sul da Namíbia a Moçambique, uma extensa similaridade entre a iniciação feminina ao que ela pesquisou na Zâmbia, chamada de Chisungu. Em seu livro Chisungu, 1956, Richards descreveu ser um tabu para homens e meninas não iniciadas, apresentando desenhos desses símbolos sagrados, cânticos e interpretações. Os mbusa, emblemas sagrados feitos em cerâmica, fazem parte de um conjunto de rituais administrado por uma mulher mais idosa, chamada de Nachimbusa, que teria como função transformar a menina em mulher preparada para a vida matrimonial - sendo preparados para a cerimônia e quebrados em seu encerramento. Muito embora as relações sexuais pudessem ocorrer, ou melhor, fossem comuns antes do casamento, principalmente com o futuro marido, havia vários cuidados para não acarretasse gravidez. Neste caso o uso de ervas era administrado para esse fim.

$\mathrm{Na}$ véspera do casamento, o Chisungu definitivamente a transformaria em mulher com a autorização e a demanda para engravidar. Victor Turner (1967) que também se debruçou sobre os Ndembu da Zâmbia, elaborou as três fases da iniciação apontadas por Van Gennep (1909). Inicialmente há a separação da comunidade e de suas práticas rotineiras, criando um ambiente marginal. Em seguida, a iniciada é inserida em domínio cultural desconhecido, distante do passado, para promover sua transformação em adultos. Por fim, a agregação comunitária desse novo membro. Por isso, como afirmou Gosselain (1999) sobre as cerâmicas, o produzir e os usos do mbusa no Chisungu tem o poder de transformar a menina em mulher assimile conhecimentos sobre a vida matrimonial e a importância social desse novo status. 
Mapa 1. Abrangência na África Central do Chisungu

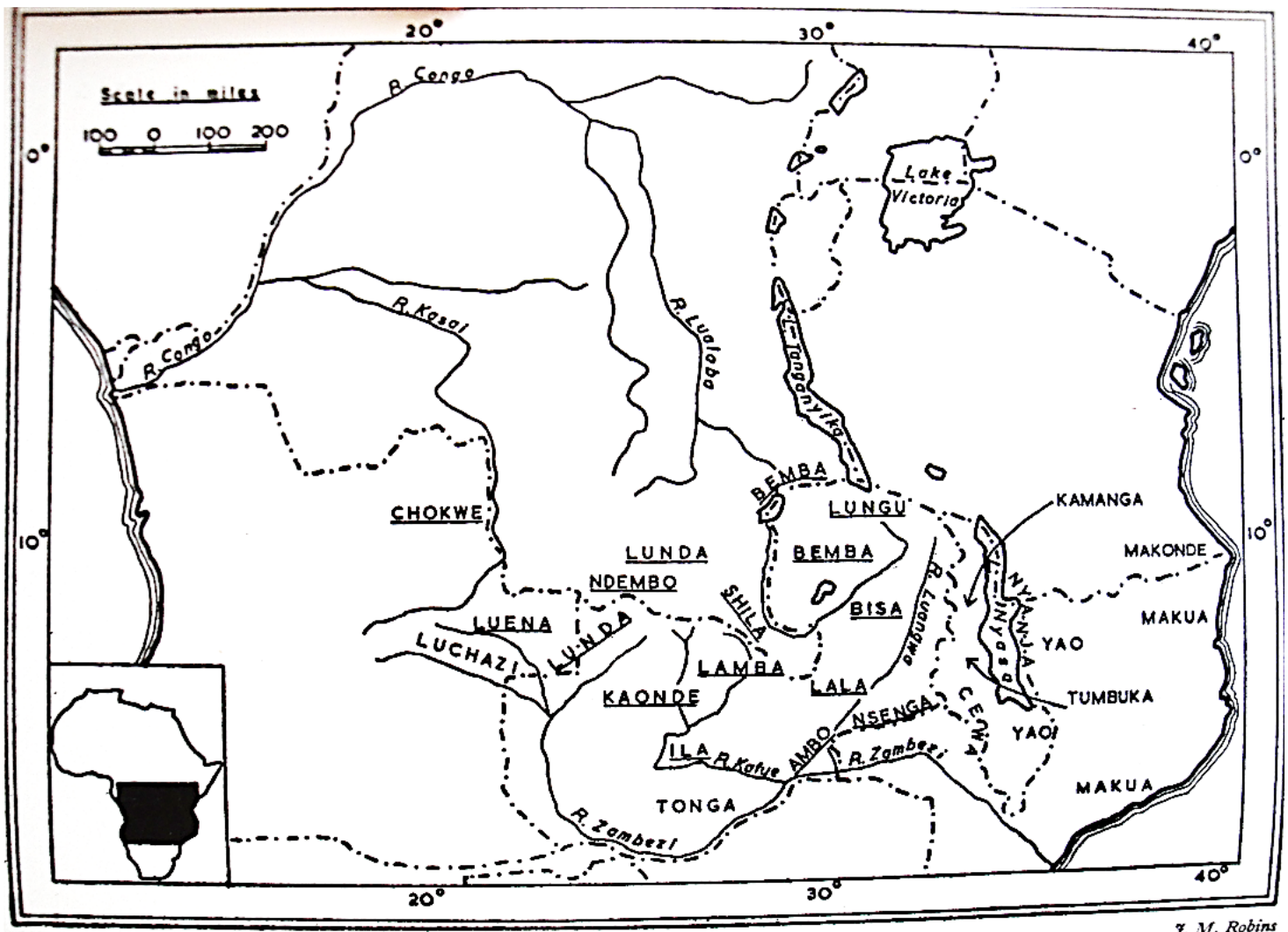

Fonte: RICHARDS, 1956, p. 24.

As fronteiras territoriais são marcadas com traçados

As populações que praticam a cerimônia estão sublinhadas.

Sobre a população Bemba, Andrew Roberts (1973) enfatizou a sobreposição ocorrida após a instalação do sistema do Chitimukulu, como centralidade das relações religiosas e políticas ocorridas no século XVIII. Como podemos observar pelos estudos de Andrey Richards (1956) e Thera Rasing (1994), a centralidade das aprendizagens cotidianas Bemba e de seus vizinhos estava em torno da figura da mulher. Por isso a importância social contínua do Chisungu como legitimidade do matrimônio orbitando em torno da identidade coletiva. 
Figura 3 - Mundu (leão): emblema sagrado usado no ritual do Chisungu

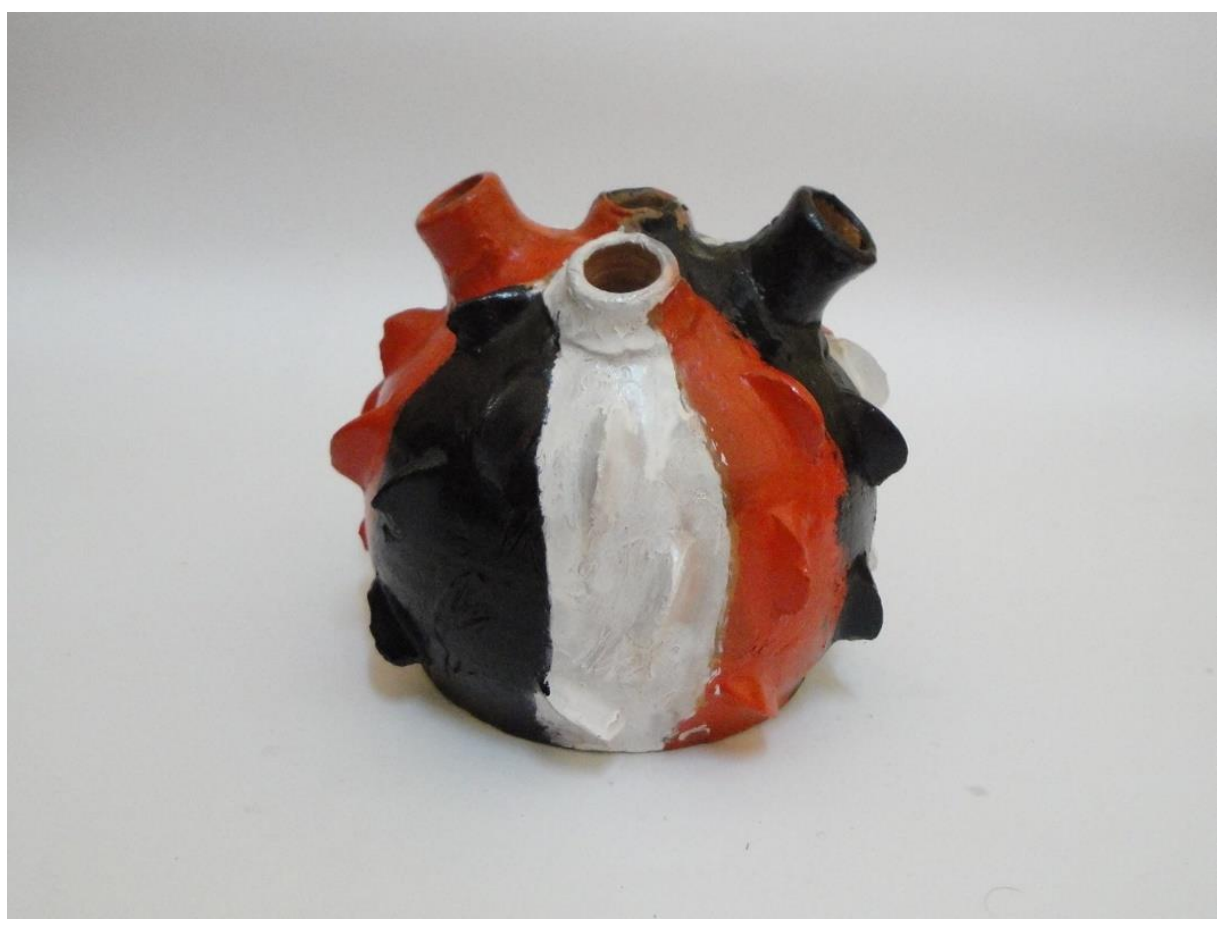

Fonte: Arquivo do autor.

Esse mbusa nomeado de leão (mundu em Bemba arcaico) é uma cerâmica feita com três orifícios na superfície que assoprando um orifício e tampando um outro faz o som parecido com o rugido do leão. Como observamos acima com Gosselain (1999), as cerâmicas ocupam e direcionam práticas sociais que transformam a vida social, neste caso do Chisungu. Para todo mbusa há cantigas que produzem seu correspondem a seu sentido social, cantado durante a cerâmica pela Nachimbusa e suas auxiliares. Citando um trecho da música, transcrito por Corbeil (28): Shakita ku mutopoto (O leão está rugindo na plantação de feijão) / Pali uko, Mundu asumine nama. (Em algum lugar, o leão apanhou uma presa). Mutopoto significa feijões e também o rugido do leão. De acordo com a interpretação dada pelo autor, em um sentido amplo, o rugido do leão nomeia a ação do esposo quanto da esposa que rugem para avisar os que estão ao redor para não se aproximarem de sua presa. Com efeito, o Chisungu transforma as relações sociais e determina quais ações devam ou não acontecer e quais são esperadas dos envolvidos mutuamente. Embora os Bemba fossem poligâmicos o adultério não era admissível. Os relatos que Roberts (1973) apresenta era de que o chefe poderia vender os envolvidos e seus familiares como escravos para os árabes.

Se por um lado havia uma desconsideração da mulher por parte da posição social 
ocupada pelos chefes, pelas autoridades coloniais e missionários, essa aprendizagem foi mantida pelos vínculos afetivos cotidianos entre as mulheres. De forma intrínseca aos processos migratórios, há a incorporação de conhecimentos sobre a identidade bemba em sua permanência na Zâmbia. Esse esquema foi incorporado na qualidade de indicativo de determinadas famílias serem sucessoras ao aro de Chiti, símbolo do poder supremo bemba. Recorrendo à ascendência direta de Mumbi Mukasa, a esposa-deusa de Mukulumpe, o bakabilo (conselheiro) do Chitimukulu escolheria seu sucessor pela mesma linhagem de sua mãe, Chandamukulu. Os bakabilo também ocupavam a posição de líderes de vilarejos e guardiões do sítio mortuário do Chitimukulu.

O status de conhecimento da identidade bemba é mantido por três aspectos estruturantes dessa reprodução, como analisa Barth (2002): um conjunto significativo de afirmativas, formas de transmissão das representações e organização social. Na interdependência desses três aspectos, um corpus de ideias reconhecidas sobre a identidade bemba, instituído por objetos, posições e mito da gênese bemba já ocupadas pelo clã crocodilo da Chandamukulu e transmitido e institucionalizado pelo próprio sistema do Chitimukulu. Com efeito, orbitam sobre a Chandamukulu a centralidade de experiências cotidianas válidas da mulher e de linhagem divina, os descendentes de Nkole, irmão de Chiti, que ocupam uma posição de destaque social em Lubemba, território bemba, porém não podem ser escolhidos para suceder da descendência de Chiti em tal sistema.

É muito provável que sendo uma prática ampla de sentido similar sua dissipação tenha ocorrido por um longo período entre os grupos assinalados. Todos estes grupos são falantes bantos. Essas duas características ocorreram em um cenário banto que foi atingido pela divisão inicial e tardia (Figura 1-a e 1-b). Outras ondas migratórias posteriores surgidas a partir do Império Lunda alocaram-se a sudoeste pelos Chokwe, ao sul em Kazembe e a sudeste pelos Bemba. Um outro grupo banto, os Bisa, teria chegado bem antes, quando ainda ocorriam o comércio entre as rotas do interior de mwene mutapa ou Monomotapa até Kuba, passando pelo império Lunda até Lualaba e Songye, desde o século XVI, como se constatou pelo achado das cruzes de ferro nessa extensão territorial (M'KBOLO, 2009).

Por um lado, há dinâmicas migratórias que identificam grupos e os distanciam entre si. Por outro, há proximidades simbólicas que produzem interações significativas 
intercambiáveis perpetuando aprendizagens de longa duração caracterizando as constelações orbitando em torno da expansão banta.

Durante a mobilidade social é comum que a presença majoritária de homens, que por eventos de assimilação decorrente de status e posição social procurem filiar-se a famílias que proporcionem, mutuamente, recompensas pré-estabelecidas. Além disso, determinados períodos de estiagem e caça afastavam os homens durante longos períodos, intensificando a atuação das mulheres para destacar valores, crenças e práticas que determinaram quais conhecimentos corroboram a identidade coletiva (BARTH, 2002). Dessa forma, observamos que a matricentralidade das aprendizagens prevaleça em comparação a determinação masculina (uroxicentralidade). Como já relatamos acima, o cotidiano familiar e afetivo desempenhou papel crucial para a difusão do islamismo nas rotas interior-costa (SPERLING, 2000) e relativas à iniciação do Chisungu.

Mesmo depois da chegada dos Bemba, como dos Chokwe por volta do século XVIII, a imposição do culto dos novos chefes Bemba, mipashi, às comunidades bantas locais se sobrepunha ao culto do antepassado não-Bemba (nkishi) desempenhado pelas mulheres (DA SILVA, 2015). Porém este culto não foi abandonado como os migrantes Bemba esperavam. Ao contrário, a abrangência e relevância da mulher nas sociedades bantas zambianas mantiveram sua centralidade nas aprendizagens cotidianas, como vimos operar o uso e a produção de cerâmicas ao longo da expansão banta. Podemos considerar com Rasing (1995) que houve uma negociação pela categoria assimilante da ancestralidade para remodelar as constelações Bemba: a ancestralidade dos chefes migrantes Bemba pelos ritos reais (mipashi) e a ancestralidade feminina das populações locais pelo rito de iniciação (Chisungu).

Considerações finais

As comunidades bantas precisam ser analisadas em seu processo expansionista com outros recortes analíticos. Buscamos demonstrar que a Antropologia da Educação pode ser um instrumento científico para investigar dinâmicas de aprendizagens relativas à mobilidade social e à difusão de categorias simbólicas. Por meio dos estudos linguísticos observamos a incorporação de categorias estrangeiras no interior de constelações de aprendizagens bantas: o uso e a produção de cerâmicas, a incorporação do islamismo e do suaíli em esquemas religiosos e numéricos e a matricentralidade nas 
relações cotidianas e afetivas.

Outro desafio aliado a esse enfoque de aprendizagens sociais foi o de se debruçar sobre um longo período espaciotemporal, que denominamos de aprendizagens de longa duração e em larga escala. Com esse instrumental analítico foi possível dimensionar os comportamentos sociais que perpassaram as comunidades bantas sem se pautar em simplificações totalizantes.

Observamos que não é preciso recair em uma homogeneização banta como uma única categoria embora ainda haja muitas lacunas a serem respondidas. A questão é que esse trabalho pôde auxiliar a entender que o comportamento social pode ser compreendido por situações cotidianas indicadoras da experiência humana em vínculos afetivos. Se de um lado as Nachimbusa produzem e reproduzem o conhecimento que transforma a menina em mulher, próximo a um campo que poderia ser chamado de ortodoxia pela legitimidade e reconhecimento social das atoras envolvidas, por outro os doutos islâmicos não acentuam igualmente a negociação de aprendizagens com a culturas locais realizadas por atores e atoras periféricas como mulheres, escravos e porteiros - nem mesmo Sufi.

Em resumo, é possível investigar aprendizagens sociais ocorridas durante séculos desde que o foco não seja uma epistemologia centrada em experiências humanas de uma única geração como parâmetro para séculos de aprendizagens coletivas. Mas dimensionando aprendizagens reconhecidas, como é o caso de múltiplas direções e em momentos diferentes da expansão banta, podemos compreender que as populações colonizadas preservaram conhecimentos incorporados em ações rotineiras pela centralidade de seus vínculos afetivos e identitários.

\section{Referenciais}

ALPERS, Edward. East Central Africa. In: LEVTZION, Nehemia, POUWELS, Randall. History of Islam in Africa. África do Sul: David Philip Publisher, 2000, Cap. 14 , p. 303-323.

BARTH, Fredrik. O guru, o iniciador e outras variações antropológicas. Rio de Janeiro: Contra Capa, 2000.

Temáticas permanentes e emergentes na análise da etnicidade. In: VERMEULEN, Hans; GOVERS, Cora (orgs) Antropologia da etnicidade. Para além de "groups ethnics and boundaries". Lisboa: Edições Fim de Século, 2003 
fev. 2002.

An anthropology of knowledge. Current Anthropology. Vol. 43, n.1, p. 1-18,

BOSTOEN, Koen. The vocabulary of pottery fashioning techniques in great lakes bantu: a comparative onomasiological study. 4th World Congress of African Linguistics, New Brunswick 2003 Akingiyi Akinlabi and O. Adesola (ed), Köln: Rüdiger Köppe 2004a, p. 391-408.

Linguistics for the use of African history and the comparative study of Bantu pottery vocabulary. Antwerp papers in linguistics, 106, 2004b. p. 131-154. Disponível em: < http://hdl.handle.net/2013/ULB-DIPOT:oai:dipot.ulb.ac.be:2013/104852>. Acesso em: 13/01/2016.

Pots, Words and the Bantu Problem: On Lexical Reconstruction and Early

African History. The Journal of African History, Vol. 48, No. 2 (2007), p. 173-199. Disponível em:< http://www.jstor.org/stable/4501038>. Acesso em: 13/09/2015.

BEIER, Georgina. 'Yoruba Pottery', African Arts 13(3), 1980. p. 48-53.

CHITTICK, Neville. Stone anchor-shanks in the Western Indian Ocean. The International Journal of Nautical Archaeology, vol 9, n. 1, p. 73-76, feb. 1980.

COSTA E SILVA, Alberto da. A manilha e o Libambo: a África e a escravidão de 1500 a 1700. Rio de Janeiro: Nova Fronteira, 2002.

DA SILVA, Jefferson Olivatto. O expansionismo católico na Bembalândia. Curitiba: Editora Prismas, 2015a.

As resistências africanas diante das medidas preventivas coloniais contra a doença do sono na Zâmbia (1890-1920). História: Questões \& Debates, vol.62, n.1, , jan./jun. 2015b. p. 73-105

DAVIS, Hunt. Encyclopedia of African History and Culture: The Colonial Era: 1850 to 1960,2005

DE FILIPPO, Cesare; BOSTOEN, Koen; STONEKING, Mark; PAKENDORF, Brigitte Bringing together linguistic and genetic evidence to test Bantu expansion. Proceedings of Royal Society B, 2012, 279, p. 3256-3263. Disponível em:<

http://rspb.royalsocietypublishing.org/content/early/2012/05/17/rspb.2012.0318>.

Acessso em: 09/11/2015

DE HEUSCH, L. Le roi ivre ou l'origine de l'état. Paris: Gallimard, 1972.

Rois nés d'un coeur de vache. Paris: Gallimard, 1982.

EL-ROUAYHE, Khaled. Heresy and Sufism in the Arabic-Islamic world, 1550-1750:

Some preliminary observations. Bulletin of SOAS, 73, 3 (2010), 357-380.

GOSSELAIN, Oliver. In pots we trust: the processing of clay and symbols in sub-

Saharan Africa. Journal of Material Culture, vol. 4, n. 2, p. 205-230, jul. 1999. 
GRAY, Richard; BIRMINGHAM, David (Eds.). Pre-Colonial African Trade: essays on trade in Central and Eastern Africa before 1900. Inglaterra, London: Oxford University Press, 1970.

GROLLEMUND, Rebecca; BRANDAFORD, Simon; BOSTOEN, Koen; MEADE, Andrew; VENDITTIA, Chris; PAGELA, Mark. Bantu expansion shows that habitat alters the route and pace of human dispersals. PNAS October 27, 2015 vol. 112, no. 43. p. 13296-13301 Disponível em:< http://eutils.wip.ncbi.nlm.nih.gov/pmc/articles/ PMC4629331/pdf/ pnas.201503793.pdf>. Acesso em: 09/12/2015.

GUTHRIE, Malcolm. Comparative Bantu: An Introduction to the Comparative Linguistics and Prehistory of the Bantu Languages [4 vols.]. London: Gregg, 196771.

HOLDEN, Clare; GRAY, Russell. Rapid radiation, borrowing and dialect continua in the Bantu languages. In: FORSTER, Peter; RENFREW, Colin. Phylogenetic Methods and the Prehistory of Languages. Reino Unido: McDonald Institute for Archaeological Research, 2006. p. 19-31.

KRAUSE, Richard A. (1985) The Clay Sleeps. An Ethnoarchaeological Study of Three African Potters. Tuscaloosa: The University of Alabama Press. 1985

LE GUENNE-COPPENS, Françoise. Changing patterns of Hadhrami emigration and social integration in East Africa. In: FREITAG, U; CLARENCE-SMITH, W.G. (Eds). Hadhrami Traders, Scholars and Statesmen in the Indian Ocean, 1750s-1960s. Leiden: Brill, 1980. p. 157-174.

Les Swahili : une singularité anthropologique en Afrique de l'Est. Journal des Africanistes, 72, 2, p. 55-70, 2002.

MALKKI, Liisa. National Geographic: The Rooting of Peoples and the Territorialization of National Identity among Scholars and Refugees. Cultural Anthropology, vol. 7, n. 1, p. 24-44, feb. 1992.

MARTIN, B.G. Arab migrations to East Africa in Medieval times. The International Journal of African Historical Studies, Boston, vol. 7, n. 3, p. 367-390, 1974.

M'BOKOLO, Elikia. África Negra: história e civilizações. Do século XIX aos nossos dias. Tomo II. Porto: Edições Colibri, 2007.

MCDOUGALL, Ann. Hidden in the Household: Gender and Class in the Study of Islam in Africa. In: MCDOUGALL, Ann. Engaging with a Legacy: Nehemia Levtzion (1935-2003). Canadian Journal of African Studies / Revue Canadienne des Études Africaines, Vol. 42, No. 2/3, Cap. 18, p. 508-545, 2013. Disponível em:< http://www.jstor.org/stable/pdf/40380180.pdf?acceptTC=true>. Acesso em: 13/11/2015.

MCKEY, Doyle; LÉZINE, Anne-Marie. The impact of a major environmental crisis on species, populations and communities: the fragmentation of African forests at the end of the Holocene. Comptes Rendus Geoscience, Volume 345, Issues 7-8, p. 263-360, July-August 2013. 
NEWITT, D.D. Angoche, the slave trade and the portuguese c. I844-1910. Journal of African History, XIII, 4, p. 659-672, 1972.

NZIEM NAYWEL È, Isidore. O sistema político luba e lunda: emergência e expansão. In: OGOT, Bethwell Allan. África do século XVI e XVIII. Brasília: UNESCO, 2010, Cap. 20. vol. 6. p. 695-717.

PAGE, Willie (Ed.). Encyclopedia of African history and culture: Ancient Africa (Prehistory to 500 C.E.), vol. I. E.U.A., New York: Facts On File, 2005a.

Encyclopedia of African history and culture, African Kingdoms (500 to 1500), vol. II. E.U.A., New York: Facts On File, 2005 b.

RASING, Thera. Passing on the rites of passage: girls' initiation rites in the context of an urban Roman Catholic Community on the Zambian Copperbelt. Leiden, Holanda: African Studies Centre Series 6/1995, 1996.Martin (2008

RENAULT, Fançois. Le Cardinal Lavigerie, 1825-1892. França, Paris: Fayard. 1992. RICHARDS, Andrey. Chisungu: a girl's initiation ceremony among the Bemba of Northern Rhodesia. London: Longman: 1956.

ROBERTS, Audrey. A history of the Bemba: political growth and change in NorthEastern Zambia before 1900. London: Longman, 1973.

ROMERO, Patricia W. Mama Khadija: A life history as example of family history.In: Romero, Patricia W. (ed.), Life histories of African women. London: Ashfield Press. p. $140-158$.

RMCA - ROYAL MUSEUM OF CENTRAL AFRICA. Coleção online, 2015. Escavação feita por Jacques Nenquim em 1957. Disponível em:< http://www.africamuseum.be/collections/browsecollections/humansciences/

display_object?objectid=32790 $>$. Acesso em 13/01/2016.

RUSSELL, Thembi; SILVA, Fabio; STEELE, James. Modelling the Spread of Farming in the Bantu-Speaking Regions of Africa: An Archaeology-Based Phylogeography.

PLOS ONE. January 2014, vol. 9, Issue 1.p. 1-9. Disponível em:< http://www.plosone.org/article/fetchObject.action?uri=info\%3Adoi\%2F10.1371\%2Fjou rnal.pone.0087854\&representation=PDF $>$. Acesso em: 03/11/2015.

SPERLING, David. The coastal hinterland and interior of East Africa. In: LEVTZION, Nehemia, POUWELS, Randall. History of Islam in Africa. África do Sul: David Philip Publisher, 2000, Cap, 13, p. 273-302.

TURNER, Victor. The forest of symbols. Nova Iorque: Cornell University Press, 1967.

VANSINA, Jan. L'homme, les forêts et le passé en Afrique. In: Annales. Économies, Sociétés, Civilisations. 40 année, N. 6, 1985. p. 1307-1334. Disponível em:<10.3406/ahess/1985.283239>. Acesso em: 13/12/2015 
New Linguistic Evidence and 'the Bantu Expansion'. The Journal of African History, Vol. 36, No. 2 (1995), p. 173-195. Disponível em:<http://www.jstor.org/ stable/182309>. Acesso em: 20/08/2015.

How to distil words and obtain culture history. History in Africa, vol. 33, 2006. p. 499-511. Disponível em: < http://muse.jhu.edu/journals/hia/summary/v033/

Recebido: 02/05/2016

Received: 05/02/2016

Aprovado: $30 / 05 / 2016$

Approved: 05/30/2016 